\title{
Correction: Additive-free continuous synthesis of silica and ORMOSIL micro- and nanoparticles applying a microjet reactor
}

\author{
Christina Odenwald ${ }^{1} \cdot$ Guido Kickelbick $\mathbb{( D}^{1}$
}

Published online: 20 January 2020

(c) Springer Science+Business Media, LLC, part of Springer Nature 2020

\section{Correction to: Journal of Sol-Gel Science and Technology} https://doi.org/10.1007/s10971-018-4626-x

Unfortunately, the original article was published with wrong ESM files. The correct ESM files are replaced with the existing files.

The original article can be found online at https://doi.org/10.1007/ s10971-018-4626-X

Supplementary information The online version of this article (https:// doi.org/10.1007/s10971-019-05200-2) contains supplementary material, which is available to authorised users.

Guido Kickelbick

guido.kickelbick@uni-saarland.de
Inorganic Solid State Chemistry, Saarland University, Campus Building C4 1, 66123 Saarbrücken, Germany 